\title{
Severity of Illness and Risk of Readmission to Intensive Care: A
}

\section{Meta-analysis.}

Steven A. Frost ${ }^{1,2}$, Evan Alexandrou ${ }^{1,2,3}$, Tony Bogdanovski ${ }^{1,2}$, Yenna Salamonson ${ }^{2}$, Patricia M. Davidson ${ }^{3}$, Michael J. Parr ${ }^{1,4}$ and Ken M. Hillman ${ }^{1,4}$

${ }^{1}$ Intensive Care Liverpool Hospital, ${ }^{2}$ University of Western Sydney, ${ }^{3}$ Centre for

Cardiovascular \& Chronic Care, Curtin University of Technology and ${ }^{4}$ University of New South Wales, Sydney, Australia.

Authors’ e-mail address: Steven A. Frost: s.frost@uws.edu.au

Evan Alexandrou: evan.alexandrou@sswahs.nsw.gov.au

Tony Bogdanovski: t.bogdanoski@uws.edu.au

Yenna Salamonson: y.salamonson@uws.edu.au

Patricia M. Davidson: p.davidson@curtin.edu.au

Michael J. Parr: m.parr@unsw.edu.au

Ken M. Hillman: k.hillman@unsw.edu.au

Short title: Meta-analysis of severity of illness and risk of readmission to ICU

No. of words (excluding reference list): 2221

No. of tables: 1

No. of figures: 3

Corresponding Author:

Steven A. Frost

University of Western Sydney

Campbelltown Campus, Building 7

Locked Bag 1797

Penrith South. DC 1797

New South Wales, Australia

Phone: 61246203415

Fax: 61246253161

Email: s.frost@uws.edu.au 


\begin{abstract}
Background: Almost 1 in every 10 patients who survive intensive care will be readmitted to the intensive care unit (ICU) during the same hospitalisation. The association between increasing severity of illness (widely calculated in ICU patients) with risk of readmission to ICU has not been systematically summarized.
\end{abstract}

Objective: The meta-analysis was designed to combine information from published studies to assess the relationship between severity of illness in ICU patients and the risk of readmission to ICU during the same hospitalisation.

Data Sources: Studies were identified by searching MEDLINE (1966 to August 2008), EMBASE (1980 to 2008), and CINAHL (1982 to August 2008).

Review methods: Studies included only adult populations, readmissions to ICU during the same hospitalisation and reports of valid severity of illness index.

Results: Eleven studies (totaling 220000 patients) were included in the meta-analysis. Severity of illness (APACHE II, APACHE III, SAPS and SAPS II) measured the time of ICU admission or discharge, was higher in patients readmitted to the ICU during the same hospitalisation compared to patients not-readmitted (both $p$-values < 0.001). The risk of readmission to ICU increased by $43 \%$ with each standard deviation increase in severity of illness score (regardless if measured on admission to, or discharge from the ICU) (odds ratio $(\mathrm{OR})=1.43$, 95\% confidence interval $(\mathrm{CI})=$ 1.3-1.6).

Conclusions: A relationship between increasing intensive care severity of illness and risk of readmission to ICU was found. The effect was the same regardless of the time of measurement of severity of illness (at admission to ICU or the time of discharge from ICU). However, further research is required to develop more comprehensive tools to identify patients at risk of readmission to ICU to allow the targeted interventions, such as ICU-outreach to follow-up these patients to minimize adverse events. 


\section{Introduction}

Despite more patients surviving intensive care, approximately $10 \%$ require readmission to the intensive care unit (ICU) ${ }^{1}$. It is not clear whether the decision to discharge patients from the ICU or the level of care given to these patients on the general wards or a combination results in readmission to ICU. This event, associated with adverse health events has been highlighted as a potential marker of quality of care ${ }^{2}$. Therefore, the ability to identify patients at high risk of readmission to ICU during the same hospitalisation could allow objective decisions to be made by clinicians related to the timing of discharge from ICU, the level of care required by patients on the ward and the need for follow-up by ICU staff.

In an attempt to address this problem several authors have either collected specific data to identify risk factors for readmission to ICU, or have analyzed routinely collected data to identify predictors of readmission ${ }^{3-9}$. Some papers have specifically addressed the ability of predictors to discriminate between patients who are readmitted to ICU and those who are not ${ }^{4,10}$. Importantly, a index of severity of illness (APACHE II) ${ }^{11}$ routinely collected on admission to the ICU is by itself as accurate as a more complex predictive model that also uses characteristics of the ICU stay, such as length of stay and mechanical ventilation days ${ }^{4}$. While severity of illness is routinely calculated in patients admitted to ICU to predict in-hospital mortality in many settings throughout the world ${ }^{12}$, the association between severity of illness and the risk of readmission to ICU has not been systematically summarized. 
For this reason, a meta-analysis was designed to combine information from published studies to assess the relationship between level of severity of illness in ICU patients and the risk of readmission to ICU during the same hospitalisation.

\section{Methods}

This article was prepared in accordance with the Meta-analysis of Observational Studies in Epidemiology (MOOSE) statement ${ }^{13}$. Briefly the MOOSE statement outlines a prospective and systematic method for reporting meta-analyses of observational studies including considering the background, search strategy, methods, results, discussion, and conclusion. The rationale for choosing this method is that observational studies potentially reflect the 'usual care' of contemporary clinical practice, in contrast to the highly selected study populations identified for randomized controlled trials ${ }^{14}$. Potentially these data may be useful for informing clinical practice interventions and guideline development.

\section{Data sources and search strategy}

Studies were identified by searching MEDLINE (1966 to August 2008), EMBASE (1980 to 2008), and CINAHL (1982 to August 2008). Search strategies were adapted for all three databases by a senior hospital librarian with experience in undertaking systematic reviews. The MEDLINE search was as following:

1. intensive care units/ or intensive care/ or critical care/

2. (intensive care or critical care or icu or icus).mp.

3. 1 or 2

4. Patient Readmission/

5. (readmi\$ or re-admi\$).mp.

6. 4 or 5

7. "Severity of Illness Index"/

8. apache/

9. Health Status Indicators/

10. saps.mp.

11. "Predictive Value of Tests"/

12. risk factors/ 
13. (severit\$ adj2 illness).mp.

14. apache.mp.

15. 7 or 8 or 9 or 10 or 11 or 12 or 13 or 14

16. 3 and 6 and 15

References lists of studies identified for inclusion were hand searched to identify papers that may have been missed.

\section{Selection of studies}

Abstracts of studies identified from the three databases were independently assessed by the first two authors (SF, EA). Only studies conducted in an adult ICU were included, and any studies which did not include a validated measure of severity of illness index were excluded. Review articles were also excluded. Studies were also limited to readmission to ICU during the same hospitalisation. Any discrepancies between studies included by independent review were resolved by discussion between the first two authors. No adjudication of decisions was required by other authors.

\section{Data extraction}

Data extracted from studies included in the analysis were year of publication, country of ICU, study design, setting of study (including type of ICU medical surgical etc), duration of study, number of patients, severity of illness index tool and time of index measurement (at time of admission to, or at discharge from ICU). Mean and standard deviation of severity of illness index were also extracted from included studies. Under the assumption of an approximate normal distribution of severity of illness scores, studies that only reported median values were also included. A conservative estimate of standard deviation was obtained using the inter-quartile range (IQR). This decision was based on inspection of studies that reported both mean and median, with standard deviation (SD) and IQR. 


\section{Data synthesis and analysis}

Due to severity of illness being reported using different continuous scoring systems (Acute Physiology and Chronic Health APACHE II, APACHE III, Simplified Acute Physiology Score (SAPS) and SAPS II), the difference in severity of illness scores between patients readmitted to ICU and those who were not readmitted was calculated as using a standardised mean difference ${ }^{15}$. Calculation of a summary effects was undertaken using a inverse-variance random-effects-model (REM) ${ }^{16}$. Heterogeneity between studies was assessed using an $\mathrm{I}^{2}$ statistic and $p$-value $<0.1$ was chosen to represent evidence of statistical heterogeneity. Graphical display of the results of individual studies and summary estimates from a REM are presented as forest plots. Assessment of publication bias was assessed by inspection of funnel plots and a test of plot asymmetry using a weighted linear regression method ${ }^{17}$. Because some studies reported severity of illness at admission to ICU or at discharge (both in some cases) the association between severity of illness and risk of readmission to ICU were analyzed and presented separately, based on the time at which severity of illness was measured. Due to some studies reporting multiple severity of illness scores on admission or discharge (i.e. APACHE and SAPS), summary estimates were compared with all values and with only one severity of illness value from each study. Due to results being the same whether all values were included or only one per study and to avoid bias in confidence intervals, summary estimates only include single values for each study (APACHE given the highest priority due to being the most commonly reported). 
The risk (as an odds ratio (OR)) of readmission to ICU related to each one standard deviation (1 SD) increase of illness severity score for individual studies was estimated using the linear discriminant function ${ }^{18,}{ }^{19}$. Overall estimates of the risk of readmission to ICU for each 1-SD increase in severity of illness score was calculated using a REM. Analysis was undertaken using the meta and rmeta packages ${ }^{20,21}$ of the $\mathrm{R}$ language for statistical computing ${ }^{22}$.

\section{Results}

We identified a total of 195 potential studies to be included in the meta-analysis. After excluding review papers, including only adult populations, readmissions to ICU during the same hospitalisation, and studies that reported a valid severity of illness score: 11 studies were retained for analysis. The characteristics of these studies are presented in Table 1. Year of publication ranged from 1993 to 2008. The paper by Chen at al ${ }^{5}$ separated results based on teaching or community hospitals. Only two studies were case-control design, all other studies were inception cohorts of patients surviving an ICU stay. Combined information related to 220866 patients surviving ICU that were included in the analysis. The setting of studies included general ICUs and specific surgical, medical and cardiothoracic ICUs. Severity of illness scores reported by studies included APACHE II and III ${ }^{11,23}$, SAPS and SAPS II ${ }^{24,25}$.

Tests of heterogeneity between studies all had a $p$-value $<0.1$, regardless of the timing of measurement of severity of illness. The random-effects summary estimate of the standardised mean difference (SMD) indicated higher severity of illness scores in patients readmitted to ICU compared to those who were not readmitted, irrespective of the time at which severity of illness was measured (at admission, 
summary SMD $(\mathrm{REM})=0.35,95 \%$ confidence interval $(\mathrm{CI})=0.23-0.48 ; p$-value $<$ 0.001: at discharge SMD $(\mathrm{REM})=0.36,95 \% \mathrm{CI}=0.27-0.45 ; p$-value $<0.001)$. The summary SMD estimate of 0.35 indicates that the severity of illness score on admission was approximately $1 / 3$ of a single standard deviation higher on average in readmissions to ICU compared to non-readmissions. Forest plots of individual study SMD and the random effects estimate of the summary SMD are presented in Figure 1. The $p$-values of tests for funnel plot asymmetry were non-significant ( $p=0.23$ and $p=0.88$, for admission and discharge severity of illness score respectively). Funnel plots are presented in Figure 2.

A summary estimate of a $43 \%$ increase in the risk of readmission to ICU with each standard deviation increase in severity of illness index (measured at admission to, or discharge from ICU) was calculated using the linear discriminant function $(\mathrm{OR}=$ 1.43, 95\% CI = 1.3-1.6) (Figure 3).

\section{Discussion}

This meta-analysis has shown a relationship between increasing intensive care severity of illness score and risk of readmission to ICU in patients who survive ICU and are discharged to the ward. The effect was consistent, regardless of the timing of measurement of severity of illness (at admission to the ICU or at the time of discharge from ICU). For each standard deviation increase in severity of illness score the risk of readmission to ICU during the same hospitalisation increased by $43 \%$. Importantly, this study has shown a consistent relationship between severity of illness and risk of readmission to ICU, irrespective of severity of illness index used. 
A previous systematic review of factors associated with risk of readmission to ICU during the same hospitalisation had identified severity of illness as a predictor ${ }^{1}$. However, a meta-analysis that quantitatively combines information from published studies has not been reported. A recent editorial ${ }^{26}$ highlighted the importance of the issue of readmission to ICU. The Society of Critical Care Medicine in North America had designated readmission to ICU within 48-hours of discharge to the ward as the highest ranked quality indicator of ICU care.

A tool developed to measure workload in the ICU has been shown to identify patients at risk of readmission to ICU: the Stability and Workload Index for Transfer (SWIFT) score ${ }^{10}$. The SWIFT score has been shown to out-perform models based on the APACHE II plus characteristics of ICU stay, such as length of stay, mechanical ventilation days and days to ICU admission, in it's ability to discriminate between readmission and non-readmission patients (SWIFT area under the ROC curve (AUC) $=0.75$, versus APACHE II + stay characteristics AUC = 0.69). The SWIFT score had been validated in the same ICU in which its was developed on a later prospective cohort and in a mixed medical-surgical European ICU population (AUC 0.74 and 0.70 , respectively) ${ }^{10}$.

Importantly it should be recognized that any tools used to identify patients at risk of readmission to ICU will have difficulty predicting acute events that occur on wards, such as gastrointestinal bleeds, cardiovascular ischemia, cardiac arrhythmias and new episodes of sepsis ${ }^{26}$. Severity of illness indices routinely collected on admission to ICU, have the ability to identify patients at risk of readmission once discharged to the ward. The addition of specific follow-up by critical-care outreach teams has already 
been proposed in an attempt to reduce readmission rates ${ }^{27}$. However, more discriminating tools to separate patients who are readmitted to ICU from those who are not, may be required to ensure the appropriate allocation of resources to follow-up ICU patients post-discharge to general wards. Also, the utility of sequential daily measurement of severity of illness or organ dysfunction while in the ICU as predictors of readmission also needs to be explored in future research.

A potential limitation to this study is that studies reporting results in contrast to the included studies have been missed. We have tried to address the issue of publication bias by using visual inspection of funnel plots and a test of funnel plot asymmetry. Also the assumption of normal distribution of severity of illness scores has been applied to the analysis (both SMD and discriminant analysis). In studies that reported both median and mean values of severity of illness scores, average (median and mean) index values only differed by 2-3 points, indicating a close to normal distribution. Another potential weakness is the quality of severity of illness score data. Also this meta-analysis was restricted to APACHE II, APACHE III, SAPS and SAPS II severity of illness indices. Strengths of this study include the use of many international ICU settings, including those from North American, Australasia and European: as well as the cumulative number of patients included in the overall analysis (220 000).

In conclusion the results of this meta-analysis have shown a consistent relationship between increasing intensive care severity of illness score and risk of readmission to ICU. The effect was the same regardless of the time of measurement of severity of illness (at admission to ICU or the time of discharge from ICU). Due to a lack of well 
designed studies to systematically develop clinical tools to identify patients at risk of readmission to ICU during the same hospitalisation, further research is required. Coupled with this is a priority to identify the most appropriate and cost-effective interventions for preventing readmission to the ICU. Targeted interventions, such as ICU outreach to follow-up individuals at higher risk and mechanisms for identifying deleterious events may prevent complications in patient's who survive ICU and are transferred to the ward. 


\section{References}

1. Rosenberg AL, Watts C. Patients readmitted to ICUs* : a systematic review of risk factors and outcomes. Chest. 2000 Aug;118(2):492-502.

2. Hofer TP, Hayward RA. Can early re-admission rates accurately detect poorquality hospitals? Med Care. 1995 Mar;33(3):234-45.

3. Alban RF, Nisim AA, Ho J, Nishi GK, Shabot MM. Readmission to surgical intensive care increases severity-adjusted patient mortality. J Trauma. 2006 May;60(5):1027-31.

4. Campbell AJ, Cook JA, Adey G, Cuthbertson BH. Predicting death and readmission after intensive care discharge. Br J Anaesth. 2008 May;100(5):656-62.

5. Chen LM, Martin CM, Keenan SP, Sibbald WJ. Patients readmitted to the intensive care unit during the same hospitalization: clinical features and outcomes. Crit Care Med. 1998 Nov;26(11):1834-41.

6. Chung DA, Sharples LD, Nashef SA. A case-control analysis of readmissions to the cardiac surgical intensive care unit. Eur J Cardiothorac Surg. 2002 Aug;22(2):282-6.

7. Ho KM, Dobb GJ, Lee KY, Finn J, Knuiman M, Webb SAR. The effect of comorbidities on risk of intensive care readmission during the same hospitalization: A linked data cohort study. Journal of Critical Care. 2008.

8. Metnitz PG, Fieux F, Jordan B, Lang T, Moreno R, Le Gall JR. Critically ill patients readmitted to intensive care units--lessons to learn? Intensive Care Med. 2003 Feb;29(2):241-8.

9. Rosenberg AL, Hofer TP, Hayward RA, Strachan C, Watts CM. Who bounces back? Physiologic and other predictors of intensive care unit readmission. Crit Care Med. 2001 Mar;29(3):511-8.

10. Gajic O, Malinchoc M, Comfere TB, Harris MR, Achouiti A, Yilmaz M, et al. The Stability and Workload Index for Transfer score predicts unplanned intensive 
care unit patient readmission: initial development and validation. Crit Care Med. 2008 Mar;36(3):676-82.

11. Damiano AM, Bergner M, Draper EA, Knaus WA, Wagner DP. Reliability of a measure of severity of illness: acute physiology of chronic health evaluation--II. J Clin Epidemiol. 1992 Feb;45(2):93-101.

12. Le Gall JR. The use of severity scores in the intensive care unit. Intensive Care Med. 2005 Dec;31(12):1618-23.

13. Stroup DF, Berlin JA, Morton SC, Olkin I, Williamson GD, Rennie D, et al. Meta-analysis of observational studies in epidemiology: a proposal for reporting. Meta-analysis Of Observational Studies in Epidemiology (MOOSE) group. JAMA. 2000 Apr 19;283(15):2008-12.

14. Egger M, Schneider M, Davey Smith G. Spurious precision? Meta-analysis of observational studies. BMJ. 1998 Jan 10;316(7125):140-4.

15. Cooper HH, LV. The Handbook of Research Synthesis. Newbury Park, CA.: Russell Sage Foundation.; 1994.

16. DerSimonian R, Laird N. Meta-analysis in clinical trials. Control Clin Trials. 1986 Sep;7(3):177-88.

17. Egger M, Davey Smith G, Schneider M, Minder C. Bias in meta-analysis detected by a simple, graphical test. BMJ. 1997 Sep 13;315(7109):629-34.

18. Cornfield J. Joint dependence of risk of coronary heart disease on serum cholesterol and systolic blood pressure: a discriminant function analysis. Fed Proc. 1962 Jul-Aug;21(4)Pt 2:58-61.

19. Greenland S. Quantitative methods in the review of epidemiologic literature. Epidemiol Rev. 1987;9:1-30.

20. Lumley T. rmeta: Meta-analysis:R package version 2.14.

21. Schwarzer G. meta: Meta-analysis:R package version 0.8-2 2007. 
22. R Development Core Team. R: A language and environment for statistical computing. Vienna, Austria; 2008.

23. Knaus WA, Wagner DP, Draper EA, Zimmerman JE, Bergner M, Bastos PG, et al. The APACHE III prognostic system. Risk prediction of hospital mortality for critically ill hospitalized adults. Chest. 1991 Dec;100(6):1619-36.

24. Le Gall JR, Lemeshow S, Saulnier F. A new Simplified Acute Physiology Score (SAPS II) based on a European/North American multicenter study. JAMA. 1993 Dec 22-29;270(24):2957-63.

25. Le Gall JR, Loirat P, Alperovitch A, Glaser P, Granthil C, Mathieu D, et al. A simplified acute physiology score for ICU patients. Crit Care Med. 1984 Nov;12(11):975-7.

26. Zimmerman JE. Intensive care unit readmission: the issue is safety not frequency. Crit Care Med. 2008 Mar;36(3):984-5.

27. Ball C, Kirkby M, Williams S. Effect of the critical care outreach team on patient survival to discharge from hospital and readmission to critical care: nonrandomised population based study. BMJ. 2003 Nov 1;327(7422):1014.

28. Durbin CG, Jr., Kopel RF. A case-control study of patients readmitted to the intensive care unit. Crit Care Med. 1993 Oct;21(10):1547-53.

29. Cooper GS, Sirio CA, Rotondi AJ, Shepardson LB, Rosenthal GE. Are readmissions to the intensive care unit a useful measure of hospital performance? Med Care. 1999 Apr;37(4):399-408.

30. Ho KM, Dobb GJ, Lee KY, Finn J, Knuiman M, Webb SA. The effect of comorbidities on risk of intensive care readmission during the same hospitalization: a linked data cohort study. J Crit Care. 2009 Mar;24(1):101-7.

31. Conlon N, O'Brien B, Herbison GP, Marsh B. Long-term functional outcome and performance status after intensive care unit re-admission: a prospective survey. $\mathrm{Br}$ J Anaesth. 2008 Feb;100(2):219-23. 


\section{Figure legend}

Figure 1. Forest plots of standardised mean difference (SMD) (including 95\% confidence intervals) for each 1-SD increase in severity of illness index and risk of readmission to ICU. Severity of illness at admission panel (A) and discharge panel (B). The area of the black squares reflects the weight each study contributes to the meta-analysis (inverse variance). The diamond at the bottom of the graph is the 
summary estimate (SMD) and 95\% confidence interval from a random effects model (REM). $\mathrm{TH}=$ teaching hospital, $\mathrm{CH}=$ community hospital; ap2 and ap3 = Acute Physiology and Chronic Health Evaluation II and III, respectively: SAPS = Simplified Acute Physiology Score. Line of no-difference and summary effect lines added.

Figure 2. Funnel plots of standardised mean difference (SMD) in severity of illness index between readmissions and non-readmissions to ICU. Severity of illness at admission panel (A) and discharge panel (B).

Figure 3. Forest plots of odds ratios (including 95\% confidence intervals) for each 1SD increase in severity of illness index and risk of readmission to ICU. Severity of illness at admission panel (A) and discharge panel (B). The area of the black squares reflects the weight each study contributes to the meta-analysis (inverse variance). The diamond at the bottom of the graph is the summary estimate (odds ratio) and 95\% confidence interval from a random effects model (REM). TH = teaching hospital, $\mathrm{CH}$ = community hospital; ap2 and ap3 = Acute Physiology and Chronic Health Evaluation II and III, respectively: SAPS = Simplified Acute Physiology Score. Line of no-difference and summary effect lines added. 
Table 1. Characteristics of studies included in meta-analysis.

\begin{tabular}{|c|c|c|c|c|c|c|c|c|c|}
\hline \multirow[t]{2}{*}{ Study (reference) } & \multirow{2}{*}{$\begin{array}{c}\text { Year of } \\
\text { publication }\end{array}$} & \multirow[t]{2}{*}{ Study - design } & \multirow[t]{2}{*}{ Country } & \multirow{2}{*}{$\begin{array}{l}\text { Setting } \\
\text { (type of ICU and no. Of beds) }\end{array}$} & \multirow[t]{2}{*}{ Time frame } & \multirow{2}{*}{$\begin{array}{l}\text { No. of } \\
\text { patients }\end{array}$} & \multirow{2}{*}{$\begin{array}{l}\text { Severity of illness } \\
\text { (time measured) }\end{array}$} & \multicolumn{2}{|c|}{$\begin{array}{c}\text { Severity of illness index score } \\
\text { mean (SD) }\end{array}$} \\
\hline & & & & & & & & No- readmission & Readmission \\
\hline Durbin $^{28}$ & 1993 & Case-control & USA & $\begin{array}{l}8 \text { - bed medical } \\
16 \text { - bed surgical }\end{array}$ & 18 - months & 164 & Apache 2 (dc) & $8.8(5.2)$ & $10.6(5.5)$ \\
\hline $\begin{array}{l}\text { Chen }^{5} \\
\text { Teaching Hospitals }\end{array}$ & 1998 & Retropsective & Canada & $\begin{array}{l}2-\text { teaching hospitals } \\
\text { ICU beds } 12-30\end{array}$ & 12 - months & 2922 & Apache II (adm) & $19.8(8.1)$ & $21.4(8.1)$ \\
\hline $\begin{array}{l}\text { Chen }{ }^{5} \\
\text { Comminuty Hospitals }\end{array}$ & 1998 & Retropsective & Canada & $\begin{array}{l}4-\text { community hospitals } \\
\text { ICU beds } 7-13\end{array}$ & 12 - months & 2205 & Apache II (adm) & $13.3(7.2)$ & $16.8(6.8)$ \\
\hline Cooper $^{29}$ & 1999 & Retropsective & USA & $\begin{array}{l}28-\text { hospitals } \\
38 \text { ICUs }\end{array}$ & 1 - year & 103984 & Apache III (adm) & $43.7(22.3)$ & $54.3(24.3)$ \\
\hline Rosenberg $^{9}$ & 2001 & Retropsective & USA & 1 - medical ICU & $4-$ years & 3310 & $\begin{array}{l}\text { Apache III (adm) } \\
\text { Apache III (dc) }\end{array}$ & $\begin{array}{l}44.0(23.0) \\
34(18)\end{array}$ & $\begin{array}{l}53.0(25.0) \\
43(19)\end{array}$ \\
\hline Chung $^{6}$ & 2002 & Case-control & UK & $\begin{array}{l}17-\text { bed } \\
\text { Post cardiac surgery }\end{array}$ & 1 - year & 130 & Apache III (adm) & $57.4(\mathrm{NR})$ & $63.5(\mathrm{NR})$ \\
\hline Metnitz $^{8}$ & 2003 & Retropsective & Austria & 30 - medical, surgical and mixed & 2 - years & 15180 & Saps II (adm) & 25.0 (8.5) & 28.0 (8.5) \\
\hline Alban $^{3}$ & 2006 & Retropsective & USA & $1-20$ bed ICU & 5 - years & 10840 & $\begin{array}{l}\text { Apache II (adm) } \\
\text { Apache II (dc) } \\
\text { Saps (adm) } \\
\text { Saps (dc) }\end{array}$ & $\begin{array}{l}15.3(8.5) \\
13.8(7.1) \\
11.5(5.5) \\
10.7(4.9)\end{array}$ & $\begin{array}{l}18.4(8.9) \\
15.7(6.7) \\
13.7(5.8) \\
12.2(4.8)\end{array}$ \\
\hline Campbell $^{4}$ & 2008 & Retropsective & UK & Combined medical and surgical & 10 - years & 4366 & $\begin{array}{l}\text { Apache II (adm) } \\
\text { Saps II (adm) }\end{array}$ & $\begin{array}{l}\text { Median = } 17(\text { IQR 13-22) } \\
\text { Median = } 33(\text { IQR 23-43) }\end{array}$ & $\begin{array}{l}\text { Median }=20(\text { IQR 16-24) } \\
\text { Median }=37(\text { IQR 28-48) }\end{array}$ \\
\hline $\mathrm{Ho}^{30}$ & 2008 & & Australia & $1-22$ bed ICU & 5 - years & 16272 & Apache II (adm) & Median = $14.1($ SD 7.8) & Median = $14.0($ SD 7.0) \\
\hline Conlon $^{31}$ & 2008 & Retropsective & Ireland & $1-18$ bed & 1 - year & 1055 & Apache II (adm) & $10.6(6.6)$ & $14.4(5.1)$ \\
\hline Gajic $^{10}$ & 2008 & Retropsective & UK & 1 - ICU & 1 - year & 1131 & $\begin{array}{l}\text { Apache III (adm) } \\
\text { Apache III (dc) }\end{array}$ & $\begin{array}{l}58.1(22.9) \\
49.4(18.2)\end{array}$ & $\begin{array}{l}69.6(26.8) \\
56.8(18.8)\end{array}$ \\
\hline
\end{tabular}

Note: Apache $=$ Acute Physiology and Chronic Health Evaluation. SAPS $=$ Simplified Acute Physiology Score adm $=$ admission, $\mathrm{dc}=$ discharge, $\mathrm{NR}=$ not reported. 
(A)

Chen TH (1998) (ap2) Chen $\mathrm{CH}$ (1998) (ap2) Cooper (1999) (ap3) Rosenburg (2001) (ap3) Metnitz (2003) (saps) Campbell (2008) (ap2) Campbell (2008) (saps) Ho (2008) (ap2)

Conlon (2008) (ap2) Alban (2006) (ap2) Alban (2006) (saps) Gajic (2008) (ap3)

Summary SMD (REM)

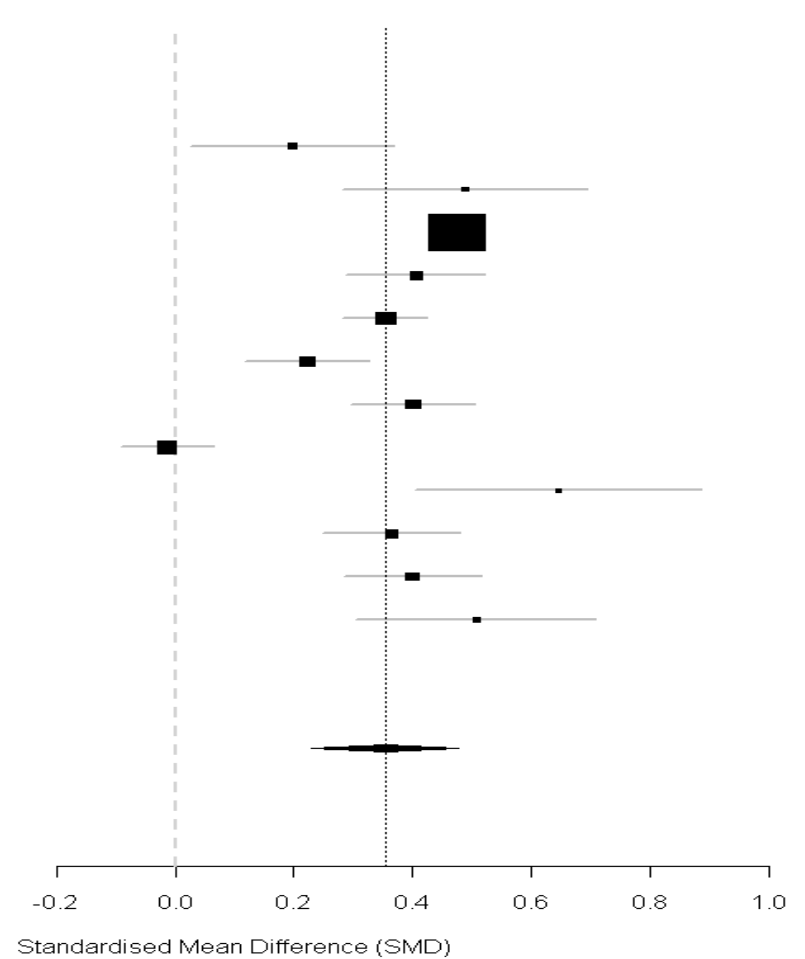

(B)

Durbin (1993) (ap2) Rosenburg (2001) (ap3) Chung (2002) (ap3) Alban (2006) (ap2) Alban (2006) (saps) Gajic (2008) (ap3) Summary SMD (REM)

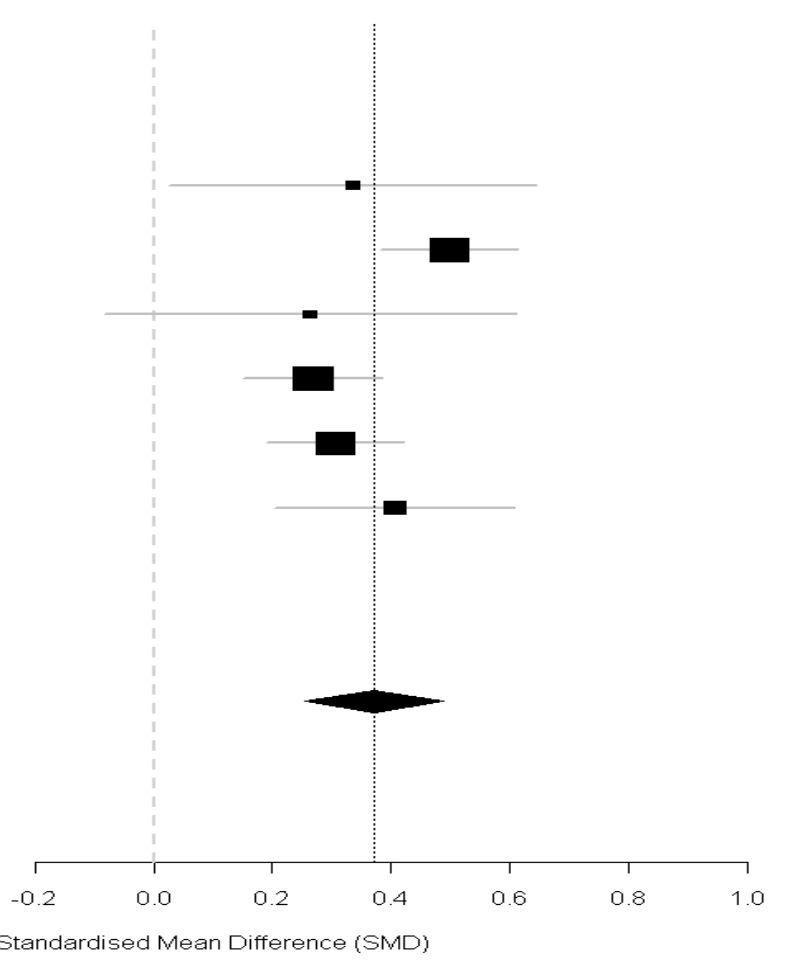

Figure 1. Forest plots of standardised mean difference (SMD) (including 95\% confidence intervals) for each 1-SD increase in severity of illness index and risk of readmission to ICU. Severity of illness at admission panel (A) and discharge panel (B). The area of the black squares reflects the weight each study contributes to the meta-analysis (inverse variance). The diamond at the bottom of the graph is the summary estimate (SMD) and 95\% confidence interval from a random effects model (REM). TH = teaching hospital, $\mathrm{CH}=$ community hospital; ap2 and ap3 = Acute Physiology and Chronic Health Evaluation II and III, respectively: SAPS = Simplified Acute Physiology Score. Line of no-difference and summary effect lines added. 


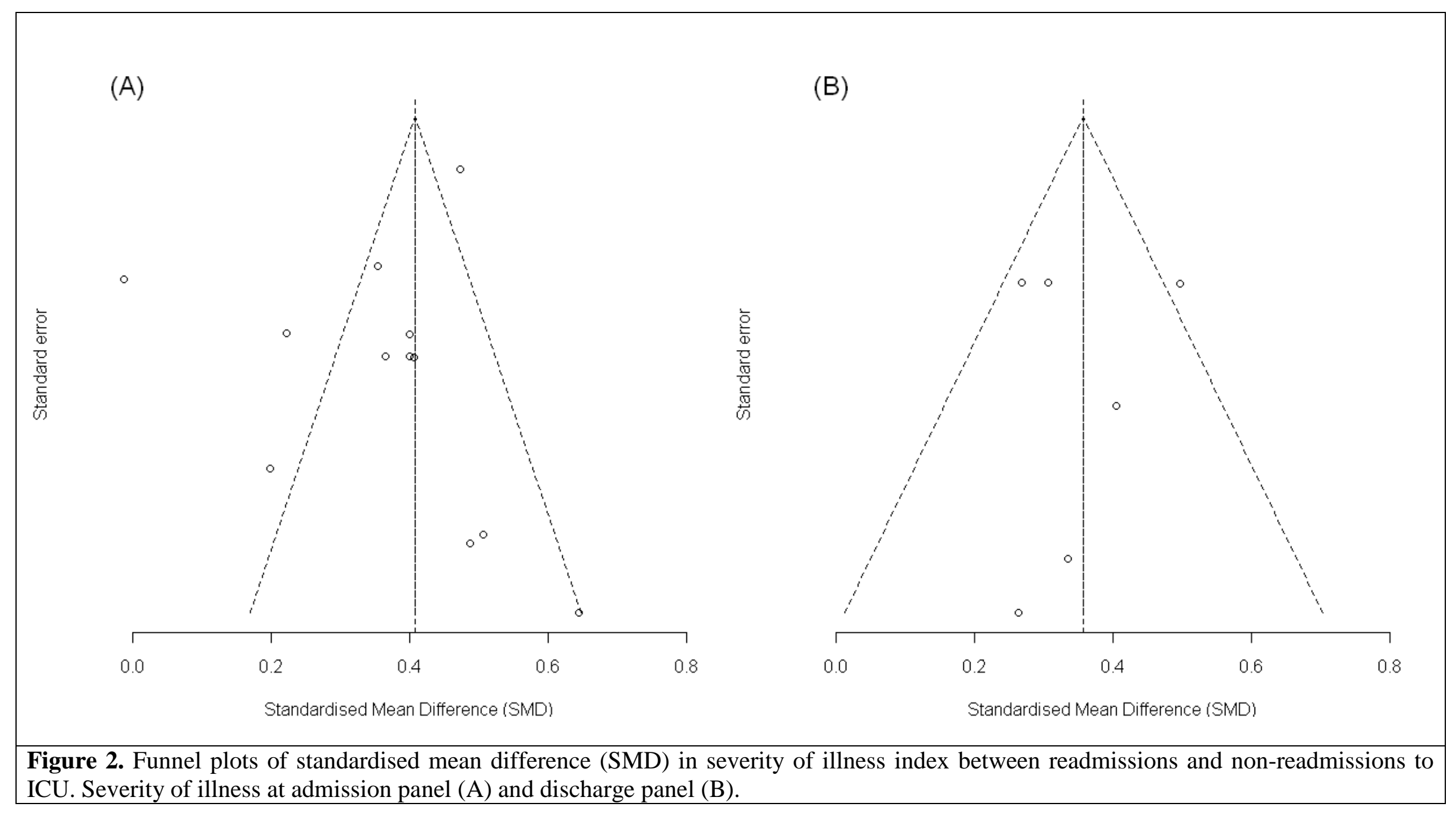


(A)

Chen TH (1998) (ap2) Chen $\mathrm{CH}$ (1998) (ap2) Cooper (1999) (ap3) Rosenburg (2001) (ap3) Metnitz (2003) (saps)

Campbell (2008) (ap2) Campbell (2008) (saps) Ho (2008) (ap2) Conlon (2008) (ap2) Alban (2006) (ap2) Alban (2006) (saps) Gajic (2008) (ap3)

summary Oda Ratio (REM)

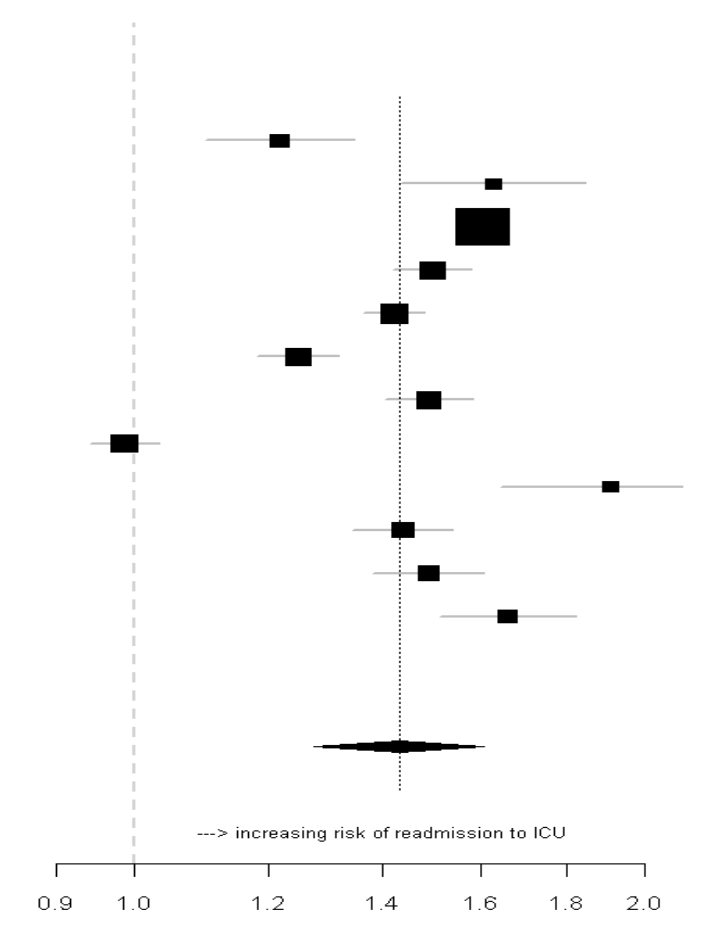

(B)

Durbin (1993) (ap2)

Rosenburg (2001) (ap3)

Chung (2002) (ap3)

Alban (2006) (ap2)

Alban (2006) (saps)

Gajic (2008) (ap3)

Summary Odd Ratio (REM)

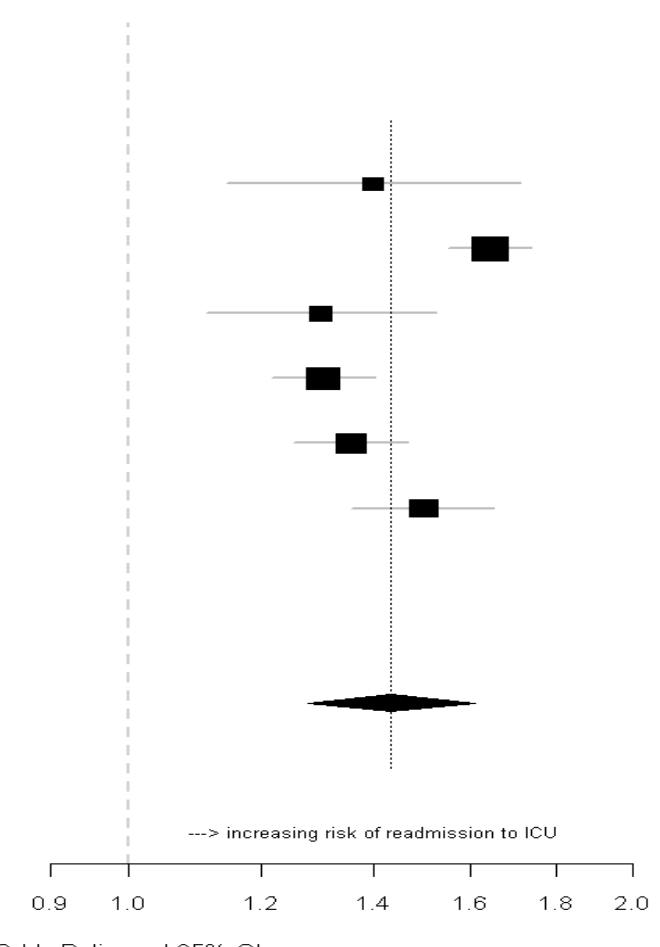

Odds Ratio and $95 \%$ C

dds Ratio and $95 \% \mathrm{C}$

Figure 3. Forest plots of odds ratios (including 95\% confidence intervals) for each 1-SD increase in severity of illness index and risk of readmission to ICU. Severity of illness at admission panel (A) and at discharge panel (B). The area of the black squares reflects the weight each study contributes to the meta-analysis (inverse variance). The diamond at the bottom of the graph is the summary estimate (odds ratio) and 95\% confidence interval from a random effects model (REM). TH = teaching hospital, $\mathrm{CH}=$ community hospital; ap2 and ap3 = Acute Physiology and Chronic Health Evaluation II and III, respectively: SAPS = Simplified Acute Physiology Score. Line of no-difference and summary effect lines added. 